\title{
Tracing back to the origin--Research on the application Value of Visual Media Design of National Traditional Patterns
}

\author{
Chunfang Wan ${ }^{1}$ \\ ${ }^{1}$ Jiangxi Vocational and Technical University of Software, Nanchang, Jiangxi, 330041, China
}

\begin{abstract}
Today's society's urban construction, industrial products, environmental protection greening, visual color and other aspects are closely related to Visual Media Design, although the national equipment, machinery and equipment, as small as daily wear, life and entertainment, China's Visual Media Design has made great development, but also presents a homogeneous, empty form of expression, lack of national characteristics. Only by implanting the traditional artistic and cultural connotation of our nation into modern design can we create artistic value and burst out new artistic spirit.
\end{abstract}

\section{Introduction}

China is a long ancient country with a history of more than five thousand years. The Chinese nation is a great nation growing and developing under the influence of more than five thousand years of traditional culture. The traditional culture of more than five thousand years contains great traditional art, among which the traditional pattern is one of the representatives. It is of great significance and value to excavate and utilize the national traditional pattern deeply for the development of the Visual Media Design level of contemporary Chinese art. National traditional patterns play an important role in the traditional art of our country, and become the development direction of Visual Media Designers to understand our traditional art culture, so how to perfect the combination of national traditional patterns and Visual Media Design, This requires a new understanding of national traditional patterns, Visual Media Design ideas and thinking into traditional national patterns, modern artistic elements and traditional national elements, so that the design conforms to modern taste and pursuit. Contemporary art pattern designers must absorb and digest the essence of our democratic traditional group art, enhance their artistic accomplishment, join Visual Media Design ideas, and combine the traditional patterns of their own nation with contemporary design ideas on the basis of a deep understanding of Chinese traditional culture.

\section{The Basic Connotation Of Chinese National Traditional Pattern And Visual Media Design}

\subsection{The Basic Connotation of Chinese Traditional Patterns}

Patterns can be seen everywhere in our daily life, everywhere, is the most common thing, the pattern comes from the historical and cultural development, is one of the oldest forms of artistic expression, Chinese traditional patterns after thousands of years of cultural development course, in different dynasties, different periods, different regions show different styles and artistic value, reflects our laboring people's understanding of life for more than five years, is the crystallization of artistic wisdom and culture, and provides a lot of valuable reference materials for modern art design. Chinese traditional patterns have developed many different artistic styles and techniques, such as ceramic patterns, painting patterns, hand-woven patterns, engraving patterns, cloth patterns, sugar patterns and so on. These beautiful traditional patterns converge the national history and cultural spirit of our country and inherit the traditional cultural connotation. The traditional pattern of our country has the combination of some, line and surface, as well as the combination of space and time, showing the artistic customs under the influence of different ancient thoughts, different religious beliefs and different regions. Chinese traditional patterns are mainly divided into folk art patterns, classical royal art patterns, primitive social patterns and minority, nomadic patterns. 


\subsection{Basic Connotation of Visual Media Design}

Modern reality, in essence, originated in the West, the industrial revolution of the 18th century, changed the development process of human society, strongly promoted the development of productive forces, produced machines, greatly improved the production efficiency of various industries, produced great economic value, improved people's living standards and cultural standards, and changed the pursuit and concept of art, directly affected the design of art, a large number of modern products need to make exquisite packaging, need to attract attention, market share, and the industrial revolution also improved the art pattern related fields of technological innovation, Modern photography and electronic printing were produced, so the industrial revolution was the main reason for Visual Media Design. In the late Qing Dynasty, the western powers invaded China and brought the elements of Visual Media Design into this ancient land, which collided violently with the traditional art patterns of our country.

With the continuous development of society, Chinese traditional patterns have entered a new era. Some single traditional patterns have been difficult to adapt to the level of modern economy and culture. Contemporary artists hope to endow Chinese traditional patterns with new connotation of the times, combine Chinese traditional patterns with Visual Media Design, and produce new artistic design elements.

\section{The Characteristics Of Chinese National Traditional Patterns.}

In order to meet the needs of life, ancient people created traditional patterns according to their own understanding and understanding of art in production and life, which have high cultural value. Make the traditional pattern have unparalleled artistic flavor.

\subsection{Formal aesthetic}

The traditional pattern of our nation, whether in artistic style, expression form and description content, develops with the change of social life, is closely related to what life sees and hears, and has a strong rhythm law and proportion coordination in the pattern expression form. The flexible use of these forms makes Chinese traditional patterns produceworthy artistic beauty in rhythm change and design concept.

\subsection{Content aesthetic}

The beauty of our national traditional patterns is distributed from the inside to the outside, and contains rich aesthetic sense in the content performance. From ancient times to modern times, we have inherited some national unique traditional groups, not only with a sense of beautiful modeling design, but also with intrinsic, profound and moving symbolic significance. This kind of meaning often comes from the ancient people's perception and cognition of some things in production and life, such as the word "Xi ", which often used in marriage, represents the meaning of double happiness and marriage happiness. These auspicious patterns also express the working people's good wishes for life, but also express the working people not afraid of difficulties, positive optimism.

\subsection{Beauty in inheritance}

China is an ancient civilization with a long history. The traditional patterns of all nationalities are handed down from generation to generation, which embodies the unremitting pursuit of beautiful things by the broad masses of people and has a sense of ceremony of inheritance. In the process of inheritance, with the continuous development of the times and civilization, the traditional national patterns are constantly changing and innovating in the course of generations of development, reflecting the strong wisdom of the working people. The inheritance and design of Chinese traditional patterns have made great contributions to the development of Chinese civilization. Today, the traditional national patterns, still continue to inherit and develop, enriched people's lives.

\section{Analysis On The Application Of Chinese Traditional Patterns In Visual Media Design}

\subsection{Analysis on the Application of Traditional National Pattern in Advertising Design}

As one of the products of history and culture, Chinese traditional patterns are still classical patterns in modern life. Through the organic combination with modern style elements, the essence elements of national patterns are refined and improved. Using modern cultural expression can reflect the inner spirit of our modern culture.

The combination of traditional patterns and modern styles is mainly reflected in the advertising notice projects in public places. The most used is the advertising poster project, such as the following figure:
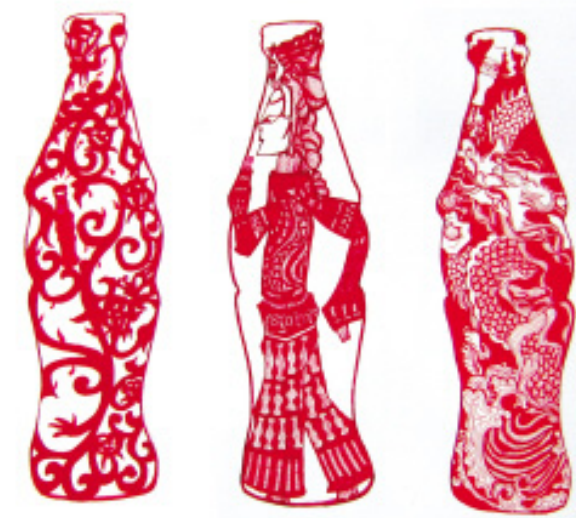

Figure 1. Advertising posters

Coca-Cola Co., Ltd., when designing advertising 
posters in China, has added a large number of traditional national pattern styles, absorbing the traditional culture-paper-cut pattern elements of our country into the Coke bottle, and by vividly displaying the traditional paper-cut elements of our country, Set the red and white pattern in the bottle, more effectively set off the Coke bottle modeling design, highlighting the three-dimensional dynamic design

In the advertising of the 2008 Beijing Olympic Games, Chinese designers fully integrated the traditional national patterns with the Olympic emblem patterns, creating a classic publicity atlas. The picture shows the elegant fairy wearing our traditional long-shirt dress, ribbon fluttering with the wind, graceful dance, gorgeous color, outstanding task image, extremely national style, showing the inner spirit of our traditional culture, expressing our country's high attention to the Olympic Games, reflecting our country's open, inclusive, atmosphere demeanor.

\subsection{Application of Traditional National Patterns in Logo Design}

The symbol represents a kind of image and expression, for example, the logo design of many banks in our country, which extensively absorbs the traditional national patterns, regards the round shape of ancient coins as the symbol of banks, represents the construction of global internationalization, and embodies the inherent meaning of dealing with coins. Let a person look, can remember deeply, achieved good social effect, as shown below:

\section{()}

Figure 2. The design of ancient coins

In the logo design of China Unicom, it also embodies the combination of traditional national patterns and Visual Media Design. The logo design of China Unicom absorbs the elements of "China knot" and Chinese red, and expresses the meaning of communication network interrelation and interlude. Vividly reflects the communication network in all directions, unobstructed internal meaning, as shown below.

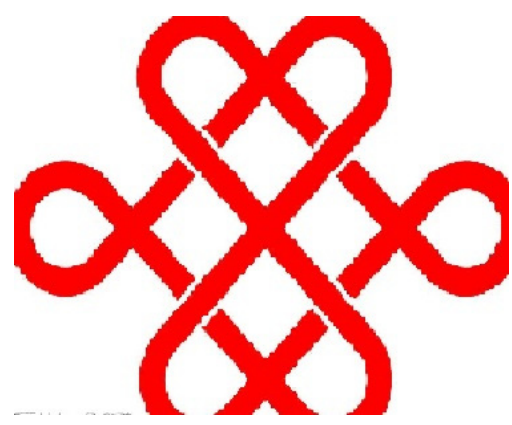

Figure 3. China Unicom logo design

\section{Conclusion}

The Visual Media Design of traditional patterns in China is also reflected in packaging design, clothing design, product design, animation design, architectural design and so on. The design idea of combining the traditional pattern of the nation with the Visual Media Design has become the popular development of the design industry in our country, which requires designers to deeply understand and master the essence and meaning of the traditional culture of our country. On the basis of Visual Media Design, national traditional patterns are reshaped and transformed into design products adapted to modern development. Under the development trend of international globalization, our contemporary designers have the responsibility to inherit and develop the essence of our national traditional culture in the design concept. In the concrete application of Visual Media Design, the spirit of Chinese traditional culture will be carried forward.

\section{Author:}

Wei Yu, unit: Nanchang Institute of Technology, Jiangxi, Nanchang 330044. Author: Yu Wei (July 26,1984), male, native: Linxiang, Hunan, nationality: Han, Master degree, Lecturer, Research interests: business Administration.

\section{Acknowledgement}

Jiangxi Province Culture and Art Science Planning Project / Project number: Research on the artistic characteristics and contemporary value of Jiangxi folk patterns in the middle and late Qing Dynasty/YG2018129

\section{REFERENCES}

1. Wu,S.Z.(1999)Pay attention to enterprise management reform[J].China Staff Education.

2. Hao,M.R.(1996)New international trends in enterprise management reform[J].business management .

3. Li,B.(1997)Viewpoint of Enterprise Management Reform[J].Management Scientific Abstracts.

4. Wang,D.H.Wang,G.L.(2013)The Importance of Contemporary Enterprise Management Reform[J]. 
knowledge economy.

5. Chen.W.(2016) The Process and Development Trend of Enterprise Management Reform in China[J]. Hebei Enterprise. 